\title{
Efficacy of short-ragweed sublingual immunotherapy tablet MK-3641 in monosensitized and polysensitized subjects
}

\author{
David I Bernstein ${ }^{1}$, Kevin R Murphy², Hendrik Nolte ${ }^{3^{*}}$, Amarjot Kaur ${ }^{3}$, Jennifer Maloney ${ }^{3}$ \\ From Canadian Society of Allergy and Clinical Immunology Annual Scientific Meeting 2014 \\ Ottawa, ON, Canada. 23-26 October 2014
}

\section{Background}

Immunotherapy for allergic rhinitis with/without conjunctivitis $(\mathrm{AR} / \mathrm{C})$ may exhibit different efficacy characteristics in patients with multiple allergen sensitizations than monosensitized patients. It has been considered that monosensitized patients may benefit more from immunotherapy than polysensitized patients. Evidence from randomized, blinded, placebo-controlled trials of Timothy grass sublingual immunotherapy tablet (SLIT-T) MK-7243 (Merck/ALK-Abelló) indicates that treatment in monoand polysensitized subjects is equally effective.

\section{Methods}

A prospective efficacy analysis was performed between monosensitized and polysensitized subjects treated with the short-ragweed SLIT-T MK-3641 (Ambrosia artemisiifolia; Merck/ALK-Abelló). Pooled data from 2 randomized placebo-controlled trials investigating MK-3641 (6 and 12 Amb a 1-U doses) were used. The primary efficacy outcome was the total combined score (TCS=symptom+medication scores) during the 15-day peak season.

\section{Results}

Differences versus placebo for the MK-3641 6 and 12 Amb a 1-U pooled groups (mono- and polysensitized subjects combined) for the peak season TCS were $20 \%$ $(-1.70$; $95 \% \mathrm{CI},-2.55$ to -0.86$)$ and $23 \%(-2.02 ; 95 \% \mathrm{CI}$, -2.87 to -1.17$)$, respectively $(P<0.001$ for both). Differences versus placebo in the monosensitized MK-3641 pool $(\mathrm{n}=175)$ were $15 \%(-1.34 ; 95 \% \mathrm{CI},-3.40$ to 0.73$)$ and $19 \%(-1.72 ; 95 \% \mathrm{CI},-3.63$ to 0.20$)$ for 6 and 12 Amb a 1-U, respectively. In the polysensitized MK-3641 pool $(\mathrm{n}=784)$ difference versus placebo were $21 \%$ $(-1.78$; $95 \% \mathrm{CI},-2.80$ to -0.75$)$ and $27 \%(-2.27$; $95 \% \mathrm{CI}$, -3.27 to -1.28 ) for 6 and $12 \mathrm{Amb}$ a 1-U, respectively.

\section{Conclusions}

In the whole study population, treatment with MK-3641 6 and $12 \mathrm{Amb}$ a $1-\mathrm{U}$ for ragweed-induced AR/C was superior to placebo. Although the sample size for the 2 subpopulations was not balanced and data must be interpreted cautiously, it appears that the treatment effect is similar in the mono- and polysensitized subpopulations, with a numerical trend of a greater treatment effect in polysensitized subjects.

\section{Trial registration}

ClinicalTrials.gov Identifiers: NCT00783198; NCT00770315.

\section{Acknowledgements}

Medical writing and editorial assistance was provided by Erin P. Scott, PhD. This assistance was funded by Merck \& Co., Inc., Whitehouse Station, NJ, USA. Editorial assistance was also provided by Jorge Moreno-Cantu, PhD, Global Scientific and Medical Publications, Office of the Chief Medical Officer, Merck \& Co., Inc., Whitehouse Station, NJ, USA.

\section{Authors' details}

${ }^{1}$ Bernstein Allergy Group, Cincinnati, OH, USA. ${ }^{2}$ Boys Town National Research Hospital, Boys Town, NE, USA. ${ }^{3}$ Merck \& Co., Whitehouse Station, NJ, USA.

Published: 18 December 2014

doi:10.1186/1710-1492-10-S2-A31

Cite this article as: Bernstein et al.: Efficacy of short-ragweed sublingual immunotherapy tablet MK-3641 in monosensitized and polysensitized subjects. Allergy, Asthma and Clinical Immunology 2014 10(Suppl 2):A31.

${ }^{3}$ Merck \& Co., Whitehouse Station, NJ, USA

Full list of author information is available at the end of the article 